\title{
Glacier velocities across the central Karakoram
}

\author{
Luke COPLAND, ${ }^{1}$ Sierra POPE, ${ }^{1}$ Michael P. BISHOP, ${ }^{2}$ John F. SHRODER, $\mathrm{Jr}^{2}$ \\ Penelope CLENDON, ${ }^{3}$ Andrew BUSH, ${ }^{4}$ Ulrich KAMP, ${ }^{5}$ Yeong Bae SEONG, ${ }^{6}$ \\ Lewis A. OWEN ${ }^{7}$ \\ ${ }^{1}$ Department of Geography, University of Ottawa, Ottawa, Ontario K1N 6N5, Canada \\ E-mail: luke.copland@uottawa.ca \\ ${ }^{2}$ Department of Geography and Geology, University of Nebraska at Omaha, Omaha, NE 68182-0199, USA \\ ${ }^{3}$ Department of Geography, University of Canterbury, Private Bag 4800, Christchurch, New Zealand \\ ${ }^{4}$ Department of Earth and Atmospheric Sciences, University of Alberta, Edmonton, Alberta T6G 2E3, Canada \\ ${ }^{5}$ Department of Geography, University of Montana, Missoula, MT 59812-1018, USA \\ ${ }^{6}$ Department of Geography Education, Korea University, Seoul 136-701, Korea \\ ${ }^{7}$ Department of Geology, University of Cincinnati, Cincinnati, OH 45221-0013, USA
}

\begin{abstract}
Optical matching of ASTER (Advanced Spaceborne Thermal Emission and Reflection Radiometer) satellite image pairs is used to determine the surface velocities of major glaciers across the central Karakoram. The ASTER images were acquired in 2006 and 2007, and cover a $60 \times 120 \mathrm{~km}$ region over Baltoro glacier, Pakistan, and areas to the north and west. The surface velocities were compared with differential global position system (GPS) data collected on Baltoro glacier in summer 2005. The ASTER measurements reveal fine details about ice dynamics in this region. For example, glaciers are found to be active over their termini even where they are very heavily debris-covered. The characteristics of several surge-type glaciers were measured, with terminus advances of several hundred meters per year and the displacement of trunk glaciers as surge glaciers pushed into them. This study is the first synthesis of glacier velocities across this region, and provides a baseline against which both past and future changes can be compared.
\end{abstract}

\section{INTRODUCTION}

The Karakoram is situated at the western end of the transHimalaya and is one of the largest glaciated areas outside of the polar regions, with nine glaciers $>50 \mathrm{~km}$ in length. Rapid uplift is occurring in this region, with evidence that this is largely driven by rapid surface erosion caused by processes such as landsliding and fluvial and glacial action (Burbank and others, 1996; Seong and others, 2008). Estimated exhumation rates are $3-6 \mathrm{~mm} \mathrm{a}^{-1}$ over the past $5 \mathrm{Ma}$ (Foster and others, 1994). However, as there are currently few direct measurements of surface processes in this region, it is hard properly to evaluate their relative importance in driving tectonic uplift. This study provides the first comprehensive determination of glacier surface velocities across the entire central Karakoram, a critical first step in the investigation of erosion rates by glaciers.

The velocities we report were derived for a wide range of glacier sizes and extents, mainly via optical image matching of satellite scenes. Clear-sky ASTER (Advanced Spaceborne Thermal Emission and Reflection Radiometer) scenes provided the main data source and velocities were derived for the period between summer 2006 and summer 2007. The image-based velocity calculations were compared with differential global positioning system (GPS) measurements made in summer 2005 and with data provided in previously published field reports. Patterns of spatial variability in measured ice velocities allow for firstorder determination of the importance of basal sliding vs internal deformation in glacier motion in this region, knowledge of which is important when quantifying likely basal erosion rates.

\section{STUDY AREA AND PREVIOUS MEASUREMENTS}

This study focuses on Baltoro glacier, Pakistan, and areas to the north and west of it, close to the border between Pakistan and China (Fig. 1). The glaciers in this area are some of the longest mid-latitude ice masses in the world: Siachen glacier is $\sim 72 \mathrm{~km}$, Hispar glacier is $\sim 61 \mathrm{~km}$, Biafo glacier is $\sim 60 \mathrm{~km}$, and Baltoro and Batura glaciers are both $\sim 58 \mathrm{~km}$ long. These glaciers are located within the central Karakoram, which is the highest, and one of the remotest and least accessible, mountain ranges on Earth (Searle, 1991). As such, little is known about many of even the most basic glaciological processes in this region.

Existing observations of glacier processes in the Karakoram are biased towards areas that are relatively accessible on the ground, such as traditional trading routes, mountain passes, and climbing routes towards major peaks such as K2. Much of the previous glaciological work has focused on the characteristics of unusual features, such as catastrophic glacier advances and outburst floods, as well as terminus advance and retreat patterns (e.g. Hayden, 1907; Mason, 1935; Desio, 1954; Hewitt, 1969; Mayewski and Jeschke, 1979; Goudie and others, 1984). In large part, previous work was driven by the particularly large concentration of surging glaciers that occur in the Karakoram (Hewitt, 1969, 1998, 2007, http://www.agu.org/eos_elec/97106e.htm).

Given the interest in surging glaciers in this region, many measurements of surface motion have been made on such glaciers. For example, Desio (1954) reported that Kutiûh glacier moved at a mean speed of $113 \mathrm{~m} \mathrm{~d}^{-1}$ based on terminus advance rates during a 3 month surge in 1953. Gardner and Hewitt (1990) measured mean surface velocities of $7.59 \mathrm{~m} \mathrm{~d}^{-1}\left(2.77 \mathrm{~km} \mathrm{a}^{-1}\right)$ from a cross-glacier profile during 


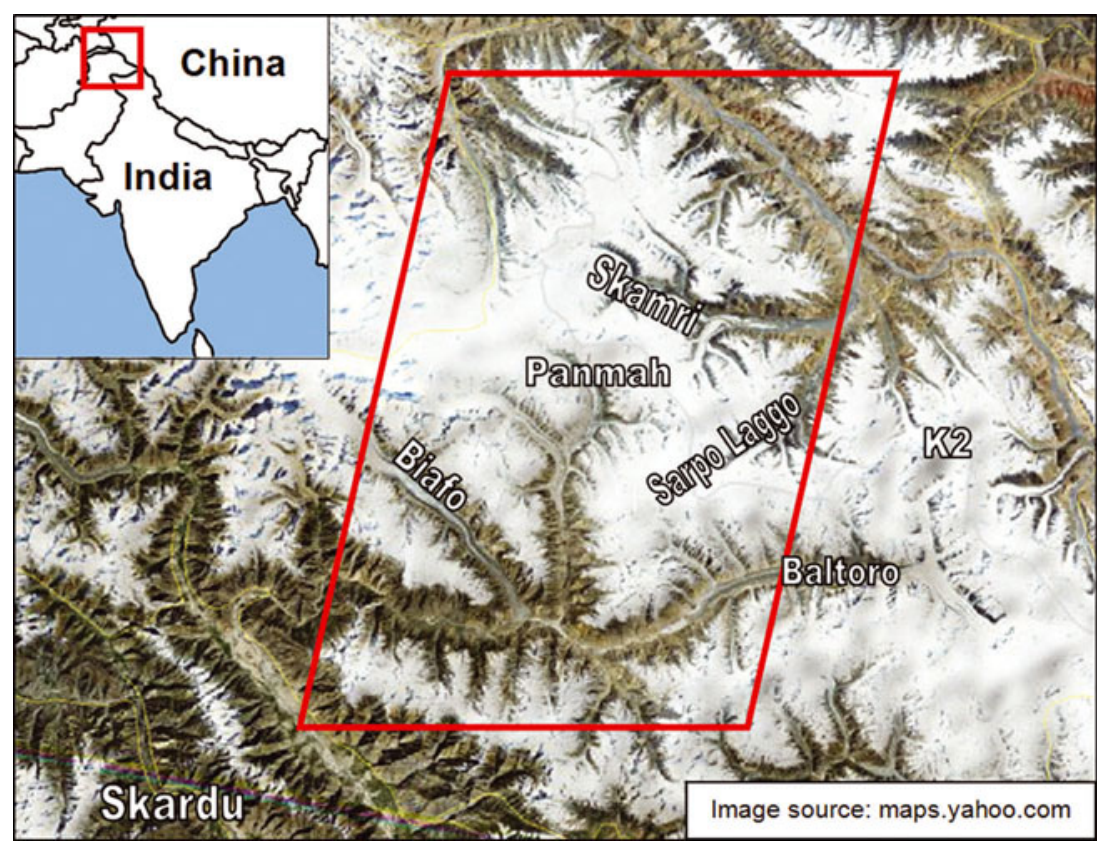

Fig. 1. Map of study area, with main features and locations labeled. The red box in the main panel indicates outline of ASTER imagery used in the feature tracking calculations.

a 1986 surge of Bualtar glacier, compared with $146 \mathrm{~m} \mathrm{a}^{-1}$ during the previous summer. Although these velocities are useful in understanding the dynamics of surging glaciers, extrapolating these findings to the many other glaciers in this region that do not surge is problematic. In addition, terminus advance rates do not equate directly to ice-surface velocities because they are influenced by, among other factors, the balance between forward ice flow and surface melting.

There have been a few previous measurements of the surface motion of non-surging glaciers in the Karakoram. The Batura Glacier Investigation Group (1979) measured velocities across Batura glacier in the mid-1970s and found an overall average of $\sim 100 \mathrm{~m} \mathrm{a}^{-1}$, with a general peak at the firn line and a decrease towards the glacier terminus. Summer speed-ups were generally $<20 \%$ of the total annual motion. Young and Schmok (1989) measured summer motion of 124$208 \mathrm{~m} \mathrm{a}^{-1}$ across a transect on Miar (Barpu) glacier in the summers of 1986 and 1987. Mayer and others (2006) used differential GPS to measure 32 stakes across Baltoro glacier in summer 2004, immediately upstream of our feature-tracking measurements. They recorded maximum velocities of $214 \mathrm{~m} \mathrm{a}^{-1}$ close to the equilibrium line at Concordia, with velocities around $100 \mathrm{~m} \mathrm{a}^{-1}$ across most of the rest of the glacier. However, Mayer and others (2006) state that comparisons with velocities that they derived from manual feature tracking of satellite imagery indicate that mean annual velocities are approximately half of those measured by GPS in the summer. They therefore concluded that basal sliding is the dominant motion mechanism for Baltoro glacier, at least during the summer melt season.

Within the region covered by this study, the only previous velocity measurements on a non-surging glacier were made on Biafo glacier by Hewitt and others (1989), who recorded summer velocities between 128 and $226 \mathrm{~m} \mathrm{a}^{-1}$ close to the midpoint of the ablation area, although winter velocities were approximately half those in the summer. Direct comparison of these velocities with the feature-tracking results is presented below in section 5 .
Examples of recent glaciological applications of the image-pair correlation method include the studies by Berthier and others (2005) and Kääb (2005). Berthier and others (2005) cross-correlated Système Probatoire pour I'Observation de la Terre (SPOT)-5 satellite images to determine the flow of mountain glaciers in the Swiss Alps, whereas Kääb (2005) used ASTER images to derive alpine glacier flow velocities in the Bhutan Himalaya. Both groups found that the feature-tracking method provided a successful alternative to synthetic aperture radar (SAR) interferometry, requiring no ground control points and enabling measurement of surface velocities in regions and over periods not covered by radar satellite missions. In the Himalaya, Luckman and others (2007) provided one of the most detailed image correlation studies to date, using satellite radar feature tracking. Using European Remote-sensing Satellite (ERS) SAR images, they determined glacier velocities and flow directions in the Everest region, and concluded that the debris cover of Himalayan glaciers makes them particularly favorable for feature tracking due to the surface patterning produced.

\section{METHODS}

In this study, ice motion was derived from feature tracking performed on pairs of clear-sky visible satellite images. These measurements were compared against velocities recorded from differential GPS measurements where available.

\subsection{Field measurements}

In summer 2005, GPS measurements of surface motion were made at six locations on lower Baltoro glacier (Fig. 2). Locations were marked with a pole drilled into the ice, or with paint on large boulders, and their position surveyed with a Trimble R7 differential GPS. Occupation times at each location were $\geq 30 \mathrm{~min}$, and the time between surveys varied between 14 and 22 days (Table 1). The data were 


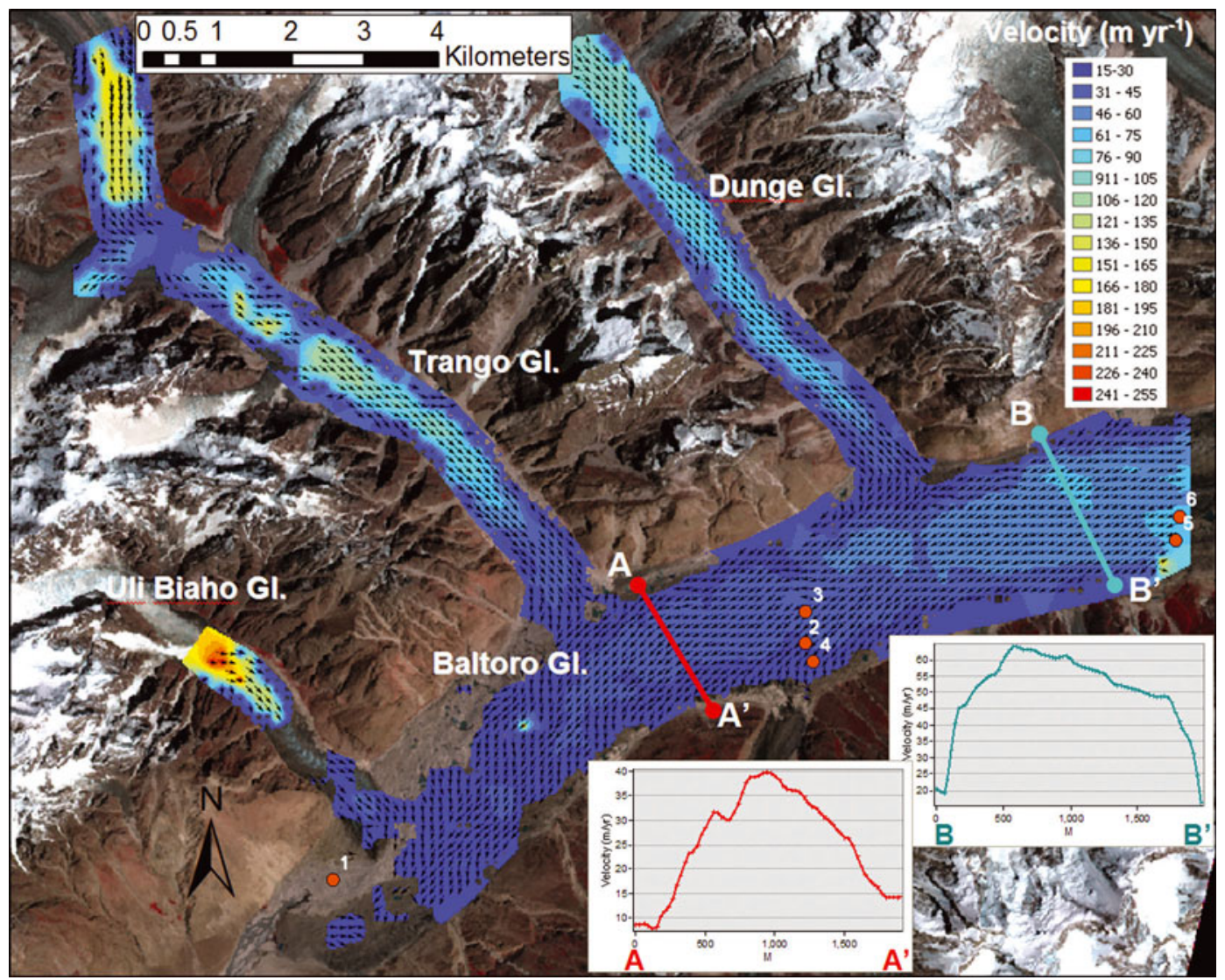

Fig. 2. Velocity patterns across Baltoro glacier and its northern tributaries derived from feature tracking. Velocity cross-profiles are shown for locations $\mathrm{A}-\mathrm{A}^{\prime}$ and $\mathrm{B}-\mathrm{B}^{\prime}$. Numbered points indicate differential GPS measurement locations (Table 1). Arrows indicate location of featuretracking match points, and calculated flow direction. Velocities not shown where $<15 \mathrm{~m} \mathrm{a}^{-1}$ or where feature tracking was not successful.

differentially corrected using a semi-permanent base station in Skardu ( $\sim 80 \mathrm{~km}$ southwest of Baltoro glacier), temporary base stations at camp sites off the edges of the glacier, or the Precise Point Positioning (PPP) solution provided by Natural Resources Canada (http://www.geod.nrcan.gc.ca/productsproduits/ppp_e.php). Positions are considered accurate to within $\pm 0.05 \mathrm{~m}$ horizontally and $\pm 0.10 \mathrm{~m}$ vertically. Note that these GPS measurements were collected prior to the 2006-07 period over which the feature-tracking measurements were made. However, they still provide the best available information concerning summer velocity patterns in the absence of any coincident field measurements from the feature-tracking period itself.

\subsection{Feature tracking}

Surface velocities were derived from pairs of clear-sky satellite scenes by automated tracking of surface features such as crevasses and surface debris between scenes. The feature tracking was undertaken with VisiCORR Windowsbased software (Dowdeswell and Benham, 2003), which is based on the IMCORR image cross-correlation software developed by Scambos and others (1992). This method enables velocities to be determined to the sub-pixel level.

Georectified ASTER L1B scenes were used as input for the analyses, downloaded from NASA's Earth Observing System Data Gateway. These images have a pixel size of $15 \mathrm{~m}$ in the visible and near-infrared bands used, and summer images

Table 1. Comparison between velocities derived from GPS vs feature-tracking (F-T) measurements on Baltoro glacier. All velocities are standardized to units of $\mathrm{m} \mathrm{a}^{-1}$. The F-T velocities (from 2006-07) are provided from the closest match point to the GPS measurements (from summer 2005), within a maximum of four pixels $(60 \mathrm{~m})$ horizontal distance

\begin{tabular}{|c|c|c|c|c|c|c|c|c|c|c|}
\hline Point & $\begin{array}{c}\text { GPS } \\
\text { latitude } \\
\circ\end{array}$ & $\begin{array}{c}\text { GPS } \\
\text { longitude } \\
\circ\end{array}$ & $\begin{array}{c}\text { GPS } \\
\text { elevation } \\
\text { m }\end{array}$ & $\begin{array}{l}\text { GPS survey } 1 \\
\text { (2005) }\end{array}$ & $\begin{array}{c}\text { GPS survey } 2 \\
(2005)\end{array}$ & $\begin{array}{c}\text { GPS } \\
\text { velocity } \\
\mathrm{m} \mathrm{a}^{-1}\end{array}$ & $\begin{array}{c}\text { GPS } \\
\text { direction } \\
\circ\end{array}$ & $\begin{array}{c}\mathrm{F}-\mathrm{T} \\
\text { velocity } \\
\mathrm{m} \mathrm{a}^{-1}\end{array}$ & $\begin{array}{c}\text { F-T } \\
\text { direction } \\
0\end{array}$ & $\begin{array}{c}\text { Velocity } \\
\text { difference } \\
\%\end{array}$ \\
\hline 1 & 35.69366 & 76.16118 & 3483.5 & 25 June & 17 July & 10.3 & 242 & 7.6 & 223 & -26.0 \\
\hline 2 & 35.72106 & 76.23045 & 3816.4 & 28 June & 16 July & 38.3 & 242 & 34.2 & 236 & -10.7 \\
\hline 3 & 35.72472 & 76.23064 & 3835.2 & 28 June & 16 July & 44.9 & 246 & 46.1 & 238 & +2.7 \\
\hline 4 & 35.71891 & 76.23159 & 3810.5 & 28 June & 16 July & 19.7 & 235 & 23.5 & 222 & +19.3 \\
\hline 5 & 35.73274 & 76.28443 & 3991.2 & 30 June & 15 July & 91.5 & 252 & 81.2 & 253 & -11.3 \\
\hline 6 & 35.73558 & 76.28507 & 3995.8 & 01 July & 15 July & 117.1 & 256 & 86.3 & 252 & -26.3 \\
\hline
\end{tabular}


were chosen to reduce the presence of snow cover. Images were also chosen based on their contrast and exposure quality, cloud cover, and acquisition characteristics; midday images from near-identical overlapping passes are most conducive to correlation processing. Ultimately, two pairs of scenes were used in the analysis: two scenes from adjacent acquisitions on 26 July 2006 (at 05:52:31 UTC and 05:52:40 UTC), and two scenes from adjacent acquisitions on 27 June 2007 (at 05:52:52 UTC and 05:53:01 UTC). Each scene covers a ground area of $60 \times 60 \mathrm{~km}$.

Initial processing involved image co-registration, followed by de-rotation of the images in ENVI software and extraction of band $3 \mathrm{~N}$ in GeoTIFF format. Selected image sections, ranging from individual tributaries to full drainage basins, were then exported as eight-bit grayscale scenes and processed using VisiCORR. The main user-set parameters in VisiCORR are the search and reference chip sizes for the image cross-correlation calculations; after extensive testing, the optimal sizes were found to be 64 and 32 pixels, respectively. A grid spacing of eight pixels between adjacent correlation attempts was found to provide the best balance between processing speed and accurate velocity determinations. The final results from the feature-tracking calculations were output as a text file from VisiCORR, corrected to values of $\mathrm{ma}^{-1}$, imported into ArcGIS software, and plotted on top of the original ASTER satellite imagery.

An assessment of the errors in the feature-tracking results was undertaken via an analysis of: (1) internal consistency of the velocity magnitudes (i.e. velocities should decrease in speed towards the glacier margins); (2) internal consistency of the velocity directions (i.e. glaciers should move in a generally downhill direction); and (3) the apparent movement of non-glaciated areas surrounding the glaciers (i.e. there should be no apparent motion in these regions). These checks indicated that the feature-tracking results generally produced realistic ice-motion patterns, with estimated errors in the velocity derivations being approximately \pm 1 pixel between scenes. As the ASTER scenes were acquired around 1 year apart, only ice motion $>15 \mathrm{ma}^{-1}$ is plotted here to remove any ambiguity in the results. In addition, velocities are not plotted where matches were not possible or where there were obvious mismatches that produced anomalously different velocities (in either magnitude or direction) from expected and/or from surrounding points.

\subsection{Determination of ice-motion mechanisms}

The relative importance of basal sliding vs internal deformation in accounting for observed surface motion can be determined from the spatial variability in velocities across transverse profiles. In areas where basal sliding dominates, ice tends to move en masse, with high but relatively constant velocities in the glacier center and rapid reductions close to the margins. This has been termed blockschollen (or plug flow) motion by some, particularly in relation to Karakoram glaciers (e.g. Finsterwalder, 1937; Kick, 1962), and is believed to represent a slab-like movement. By contrast, velocities that are generally low and increase gradually from the edges to the center of a glacier in a parabolic pattern are more likely to represent motion dominated by internal ice deformation. The surge of Variegated Glacier, Alaska, USA, provides an excellent example of the contrast between these motion types. Pre- and post-surge velocities are relatively low $\left(\sim 0.10-0.20 \mathrm{~m} \mathrm{~d}^{-1}\right)$ and have a parabolic profile during periods dominated by deformational flow, whereas profiles at the same location during surges show high and constant motion $\left(\sim 2.5-13 \mathrm{~m} \mathrm{~d}^{-1}\right)$ across almost the entire glacier when basal sliding is dominant (Kamb and others, 1985, their fig. 7). Transverse profiles have been used to infer the importance of basal sliding vs internal deformation from remote-sensing measurements on other glaciers (e.g. Fatland and others, 2003), and here we use them to make a general assessment of their relative importance on central Karakoram glaciers.

\section{RESULTS AND DISCUSSION}

Image matching was undertaken for the entire region covered by the ASTER satellite scenes, with good results produced for the ablation areas of all the major glaciers. The discussion here focuses first on the characteristics of individual drainage basins and glaciers, before presenting a regional synthesis.

\subsection{Baltoro glacier}

The ASTER imagery covered the lowermost $13 \mathrm{~km}$ of Baltoro glacier and associated tributaries. These areas tend to be heavily covered in debris, and their distinctive surface patterning makes them ideal for image matching. The velocity directions show fine details as the tributary glaciers round corners to join the main Baltoro glacier, and as the ice is channeled by the surrounding topography (Fig. 2). There is a general decrease in velocity towards the margins and termini of the glaciers, with the highest velocities reaching $>200 \mathrm{~m} \mathrm{a}^{-1}$ on icefalls in the upper parts of Uli Biaho and Trango glaciers. Velocities on the main Baltoro glacier average $50 \mathrm{~m} \mathrm{a}^{-1}$, ranging from $\sim 75 \mathrm{~m} \mathrm{a}^{-1}$ in the upper part of the study area to $<15 \mathrm{~m} \mathrm{a}^{-1}$ within the lowermost $2-3 \mathrm{~km}$ of the glacier.

As a check on the accuracy on the feature-tracking results, comparisons are made with the GPS-derived velocities from summer 2005 (Table 1; Fig. 2). In general, there is a close correspondence between the velocities measured at the six GPS locations and the feature-tracking results, particularly in relation to direction, with $<5 \%$ variation in measured direction between the two methods. There is greater variability in the magnitudes of the velocities, these being on average higher in the GPS measurements than in the feature-tracking results. However, most of the recorded differences are within the estimated feature-tracking error limits of $\pm 15 \mathrm{~m} \mathrm{a}^{-1}$. The only exception is point 6 , which was significantly faster in the GPS measurements. Mayer and others (2006) also recorded GPS (summer) velocities that were greater than the annual average derived from manual feature tracking on Baltoro glacier; summer motion was up to $100 \%$ higher than winter motion in the upper parts of the ablation area (above the region shown in Fig. 2). We did not see such dramatic summer increases in velocity in this study, however, probably because the position of the highestelevation GPS points in this study (5 and 6) is where the lowest-elevation GPS points started in the study undertaken by Mayer and others (2006).

These results indicate that Baltoro glacier experiences spatial and temporal variations in ice motion, but that these variations are not necessarily synchronous across the glacier. Higher summer velocities are commonly observed on temperate and polythermal glaciers, and are usually attributed to basal lubrication caused by subglacial water flow (Paterson, 1994). This seems likely at Baltoro glacier, as 

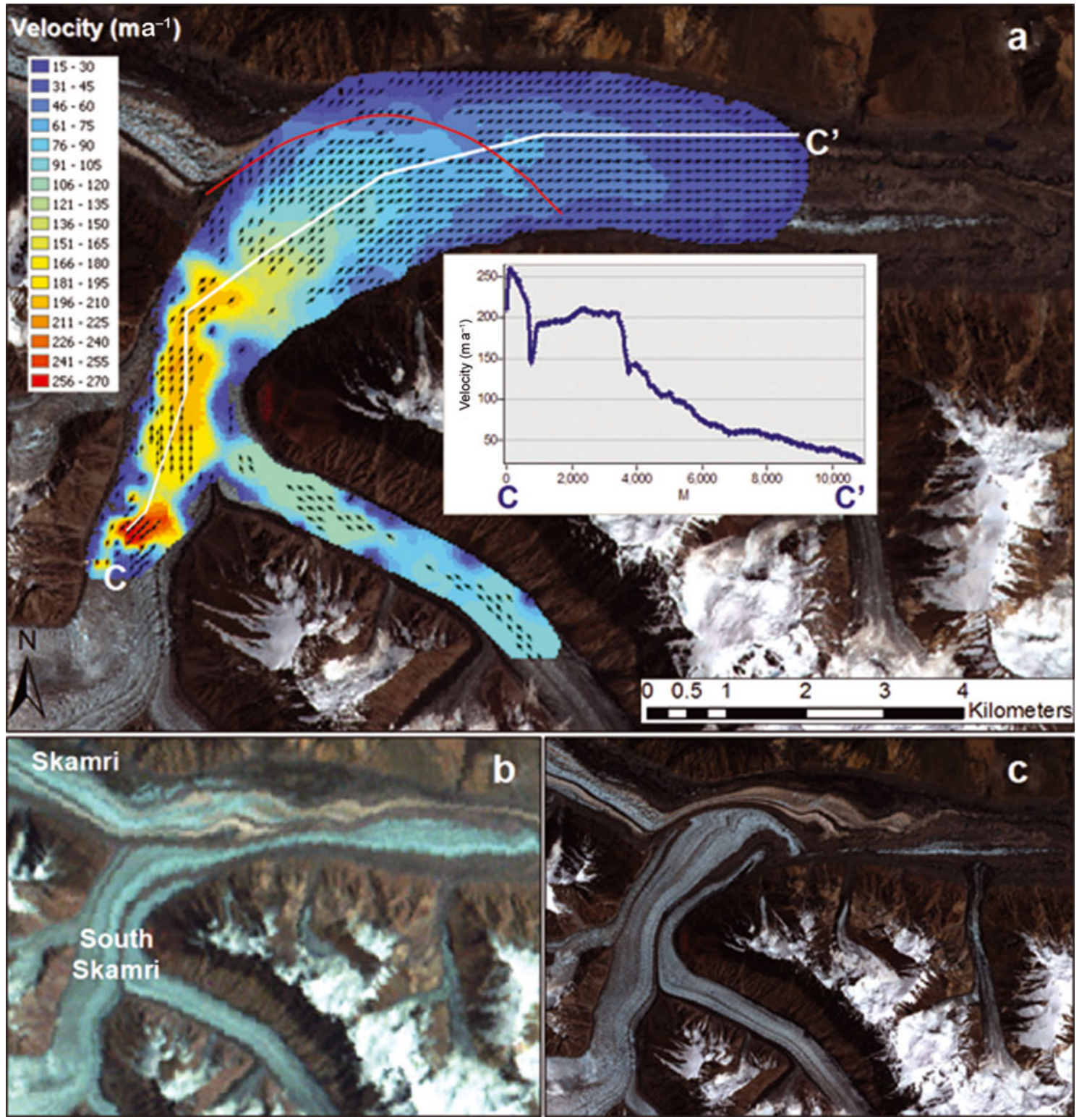

Fig. 3. (a) Velocity patterns across South Skamri and Skamri glaciers derived from feature tracking (current boundary between glaciers marked with red line). Inset shows velocity long-profile marked by white line. Arrows indicate location of feature-tracking match points and calculated flow direction. Velocities not shown where $<15 \mathrm{~m} \mathrm{a}^{-1}$ or where feature tracking was not successful. (b) Landsat image (18 July 1978) of the same region. (c) ASTER image (27 June 2007) used in (a), but without superimposed velocities.

there are many moulins and crevasses across the ablation area where meltwater can reach the glacier interior and bed, and surface melting is widespread in the summer. In summer 2005 , for example, surface melt rates of $6.5 \mathrm{~cm} \mathrm{~d}^{-1}$ were recorded close to GPS point 4 , and $5.9 \mathrm{~cm} \mathrm{~d}^{-1} 2 \mathrm{~km}$ upstream of GPS point 6 . The cross-profile B-B ${ }^{\prime}$ shows a rapid increase in velocity away from both margins, which suggests that basal sliding is the dominant motion mechanism in this part of the glacier (Fig. 2). Profile A- $\mathrm{A}^{\prime}$ shows quite a different pattern, however, with a more parabolic shape as velocities gradually rise to a peak in the center of the glacier (Fig. 2). This suggests that ice deformation is a more dominant motion mechanism close to the terminus, although basal sliding could still be important in the center of the glacier where subglacial water flow would presumably concentrate and increase basal lubrication. The very low velocities close to the margin at location A probably represent the influence of Trango glacier entering the main valley and slowing the ice immediately upstream. The greater importance of internal deformation towards the glacier terminus ties in with the GPS observations (described above) that significant increases in summer motion only occur in the upper part of our study area, and in the regions above it recorded by Mayer and others (2006).

Overall, the GPS observations indicate that the featuretracking results provide a realistic estimate of annual velocity patterns, both in terms of direction and magnitude. This gives confidence in the application of the technique to the other glaciers in this region.

\subsection{South Skamri glacier}

South Skamri glacier is located $\sim 30 \mathrm{~km}$ north of the Baltoro glacier drainage basin. It is a tributary of Skamri (Yengisogat) glacier (Fig. 3a). Historical Landsat imagery indicates a complex flow history between these glaciers. In 1978, the distortion of surface moraines suggests that Skamri glacier was surging, or had recently surged, and that it was the dominant flow unit in the basin (Fig. 3b). At this time, it 
pushed aside most of South Skamri glacier, effectively cutting it off from its lower terminus.

By 2007, it had become clear that South Skamri glacier has surged, pushing Skamri glacier aside and now making South Skamri the dominant ice-flow unit in the basin (Fig. 3c). The feature-tracking results indicate that South Skamri glacier was active throughout its ablation area at this time, with velocities $>250 \mathrm{~m} \mathrm{a}^{-1}$ over an icefall in the upper part of its ablation area (Fig. 3a). The entire lower glacier is heavily debris-covered, with the velocities gradually decreasing in an along-glacier direction and towards the margins. In general, there are high and constant velocities over most of the upper ablation area where the ice flow is channelized, with a rapid reduction in flow (from $>200 \mathrm{~m} \mathrm{a}^{-1}$ to $<100 \mathrm{~m} \mathrm{a}^{-1}$ over a horizontal distance of $\sim 1 \mathrm{~km}$ ) as the ice exits the main channel and spreads out over the wider lower valley (Fig. 3a inset).

An interesting feature of the velocity patterns shown in Figure $3 \mathrm{a}$ is that the boundary between South Skamri and Skamri glaciers occurs several kilometers upstream of the current end of the actively flowing ice $\left(>15 \mathrm{ma}^{-1}\right)$. The velocity magnitudes and directions suggest that ice input from South Skamri glacier is now causing Skamri glacier to move downstream of where the glaciers join, as there is little evidence for current inputs from the main Skamri valley. When comparison is made with earlier imagery, it is clear that Skamri glacier provided the main driver of ice flow over much of the terminus prior to 1978 (Fig. 3b), but that the main flow driver has now switched to South Skamri glacier. Beyond the currently active ice shown in Figure $3 \mathrm{a}$ is a large area of stagnant ice at the glacier snout. This was derived originally from South Skamri glacier, but was effectively cut off by the 1978 (or earlier) surge of Skamri glacier.

In terms of the dominant ice-motion mechanism, the rapid increase in velocities away from the glacier margins and towards the glacier center in the upper part of South Skamri glacier is suggestive of basal sliding in this area. By contrast, the gradual reduction in velocities across the lower ablation area is more suggestive of deformation flow. This ties in with the large, dead ice areas in front of the existing active ice front, which are currently receiving insufficient mass to drive ice flow in that area.

\subsection{Choktoi/Panmah glacier}

Choktoi glacier forms the upper part of Panmah glacier, and their combined ablation area extends $\sim 20 \mathrm{~km}$ (Fig. 4a). The ice velocities derived from feature tracking along Choktoi glacier average $\sim 100 \mathrm{ma}^{-1}$ over the central part of the ablation area, with a gradual decrease to zero over the lowermost $\sim 8 \mathrm{~km}$ where it forms Panmah glacier (Fig. 4a inset). Velocity estimates for the upper $\sim 5 \mathrm{~km}$ of the D-D' profile shown in Figure 4a have a high degree of uncertainty due to the limited number of match points over this region, with the dotted purple line providing a best estimate of velocities over this area. The overall average velocity for the $18 \mathrm{~km}$ profile shown in Figure $4 \mathrm{a}$ is $80 \mathrm{~m} \mathrm{a}^{-1}$, which suggests an average residence time of $\sim 225$ years for the ice passing through the ablation area of the Choktoi/Panmah basin. Ice velocities increase rapidly away from the margins across the central part of Choktoi glacier, which suggests that basal sliding (blockschollen) is the dominant motion mechanism for this basin.

Nobande Sobonde glacier, to the north of Panmah glacier, is largely inactive over the area shown in Figure 4a, except where tributaries join the main trunk. As discussed by Hewitt (2007), all of these tributaries have surged in the recent past. Chiring glacier surged in 1995, whereas the adjacent South Chiring (Maedan) glacier surged sometime between 2002 and 2005. South Chiring glacier still eclipses the flow from Chiring glacier, with measured velocities of up to $60 \mathrm{~m} \mathrm{a}^{-1}$ over its terminus region. However, velocities could not be derived for the upper ablation areas of Chiring, South Chiring and Second Feriole glaciers due to the low surface debris cover and few crevasses in these regions that precluded the finding of feature-tracking match points.

Second Feriole (Shingchukpi) glacier started surging in the fall or winter of 2004/05, and the velocity vectors in Figure $4 \mathrm{a}$ indicate that this surge pushed the ice of Nobande Sobonde glacier to the side (as also discussed by Hewitt, 2007). The measured velocities on Second Feriole glacier are very similar to those on South Chiring glacier, suggesting that the surging had probably stopped by 2006-07.

Unlike the relatively low velocities measured for the tributaries discussed above, the Drenmang and First Feriole glaciers showed very high local velocities of $>200 \mathrm{~m} \mathrm{a}^{-1}$ at their termini over 2006/07. Hewitt (2007) states that Drenmang glacier probably started surging in fall or winter 2004/05, with the glacier in summer 2005 overriding lateral moraines that had been ice-free for decades. Prior to this, Drenmang glacier last surged in 1977-78, with imagery from 1993 suggesting that the terminus moved at an average rate of $\sim 500 \mathrm{~m} \mathrm{a}^{-1}$ in the 15 years after this event (Hewitt, 2007). From the velocity patterns shown in Figure $4 a$ it is clear that the current terminus is very active, with Figure $4 d$ and e showing the advance of Drenmang glacier between summer 2006 and 2007. Distortion and folding of the medial moraines is also evident in these images, which provide further evidence of recent surging. Hewitt (2007) argues that the 2004-05 surge probably started in the eastern branch, and today it is this tributary that dominates flow out of the basin, with the terminus pushing into the main trunk of Nobande Sobonde glacier and constructing its flow (Fig. 4d and e). One important distinction to make is whether the 2006-07 feature-tracking velocities are indicative of a continuing surge of Drenmang glacier that started in 2004-05, or whether they represent a post-surge relaxation phase of enhanced velocities. The latter explanation seems more likely, as actual Karakoram surges typically last for only a few weeks to months (e.g. 3 months for a $12 \mathrm{~km}$ surge of Kutiah glacier (Desio, 1954); 8 days for a $3.2 \mathrm{~km}$ surge of Yengutz glacier; and 2.5 months for a $9.7 \mathrm{~km}$ surge of Hassanabad glacier (Hayden, 1907)). Furthermore, Hewitt (2007) states that it can take glaciers many years to return to pre-surge conditions after a surge has occurred. Moreover, the terminus velocities of $\sim 250 \mathrm{~m} \mathrm{a}^{-1}$ are in the range likely for a post-surge slowdown, rather than full surge conditions.

Although a surge has not previously been recorded for First Feriole glacier, from visual inspection of the ASTER scenes (Fig. 4b and c), and from the high near-terminus velocities recorded by the feature tracking (Fig. 4a), it is clear that the glacier is currently very active. The terminus advanced $\sim 250 \mathrm{~m}$ over the 2006-07 measurement period, was very steep and bulbous, and the ablation area appears to have thickened during this time (Fig. $4 \mathrm{~b}$ and c). As discussed above, the three glaciers immediately to the north of First Feriole glacier all surged in the previous decade or so (Hewitt, 2007), and old Landsat imagery (not shown) indicates that the glacier terminus was $\sim 3 \mathrm{~km}$ advanced 

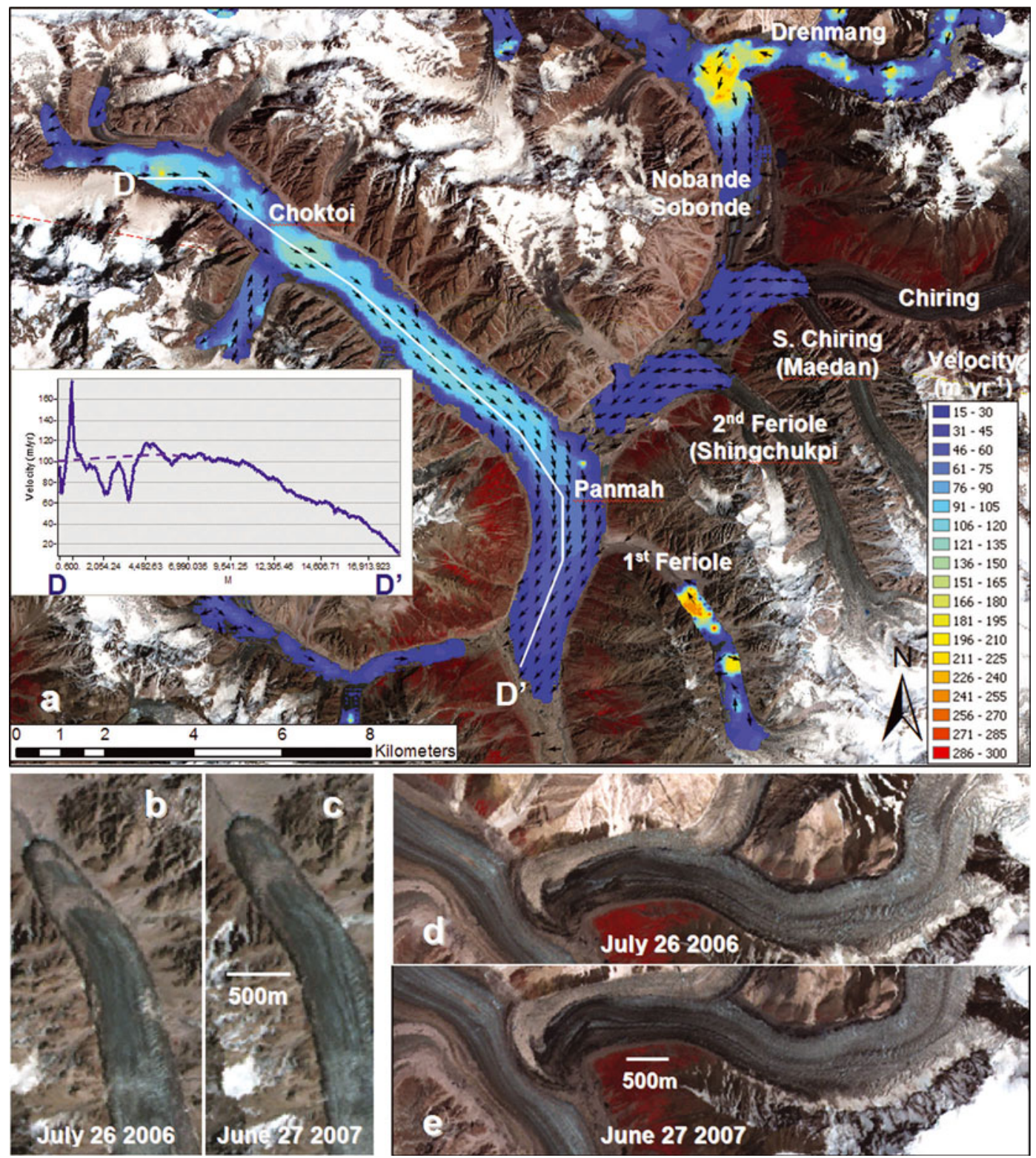

Fig. 4. (a) Velocity patterns across the Panmah glacier region derived from feature tracking. Arrows indicate calculated flow direction and are spaced every 25 pixels. Inset shows velocity long-profile marked by D-D', with dotted purple line indicating average velocity over upper $\sim 5 \mathrm{~km}$ where fewer feature-tracking match points were found. Velocities not shown where $<15 \mathrm{~m} \mathrm{a}^{-1}$ or where feature tracking was not successful. (b, c) Advance of First Feriole glacier, 2006-07. (d, e) Advance of Drenmang glacier, 2006-07.

from its present position in 1978 when surrounding glaciers were all retreating. These disparate sources of evidence all point to the fact that First Feriole glacier is likely to be a surge-type glacier, although we cannot discern whether the full surge process, or just a portion of it, was captured by the 2006-07 imagery.

\section{OVERVIEW AND CONCLUSIONS}

The feature-tracking calculations discussed here have enabled the production of the first regional map of glacier velocities across the central Karakoram (Fig. 5). It is clear that all of the glaciers in this region are active, even over their terminus regions where there are substantial supraglacial debris thicknesses (often $>1 \mathrm{~m}$ ). The rapid increase in velocity away from the margins towards the center of many of the glaciers suggests that basal sliding is a dominant motion mechanism, particularly in the middle and upper ablation areas. Further evidence for this is provided by seasonal variations in velocity recorded by GPS measurements from Baltoro glacier, discussed both here and by Mayer and others (2006). A study by Kääb (2005) in the Bhutan Himalaya indicated that large differences in dynamics were present between fast-moving north-facing glaciers and slow-moving south-facing glaciers, yet there is little evidence for a similar pattern across the central Karakoram. Instead, velocities appear to be more influenced by local conditions, with high velocities where there are icefalls, glacier surges and large glaciers. Velocities are lower towards glacier termini (where deformational flow appears to dominate), as well as in locations where ice input has been constrained or cut off by the inflow of tributaries or past surges.

Previous velocity measurements on Biafo glacier (Hewitt and others, 1989) can be used as a check on the featuretracking velocity measurements. Although these were made over 20 years ago, they provide the only known annual 


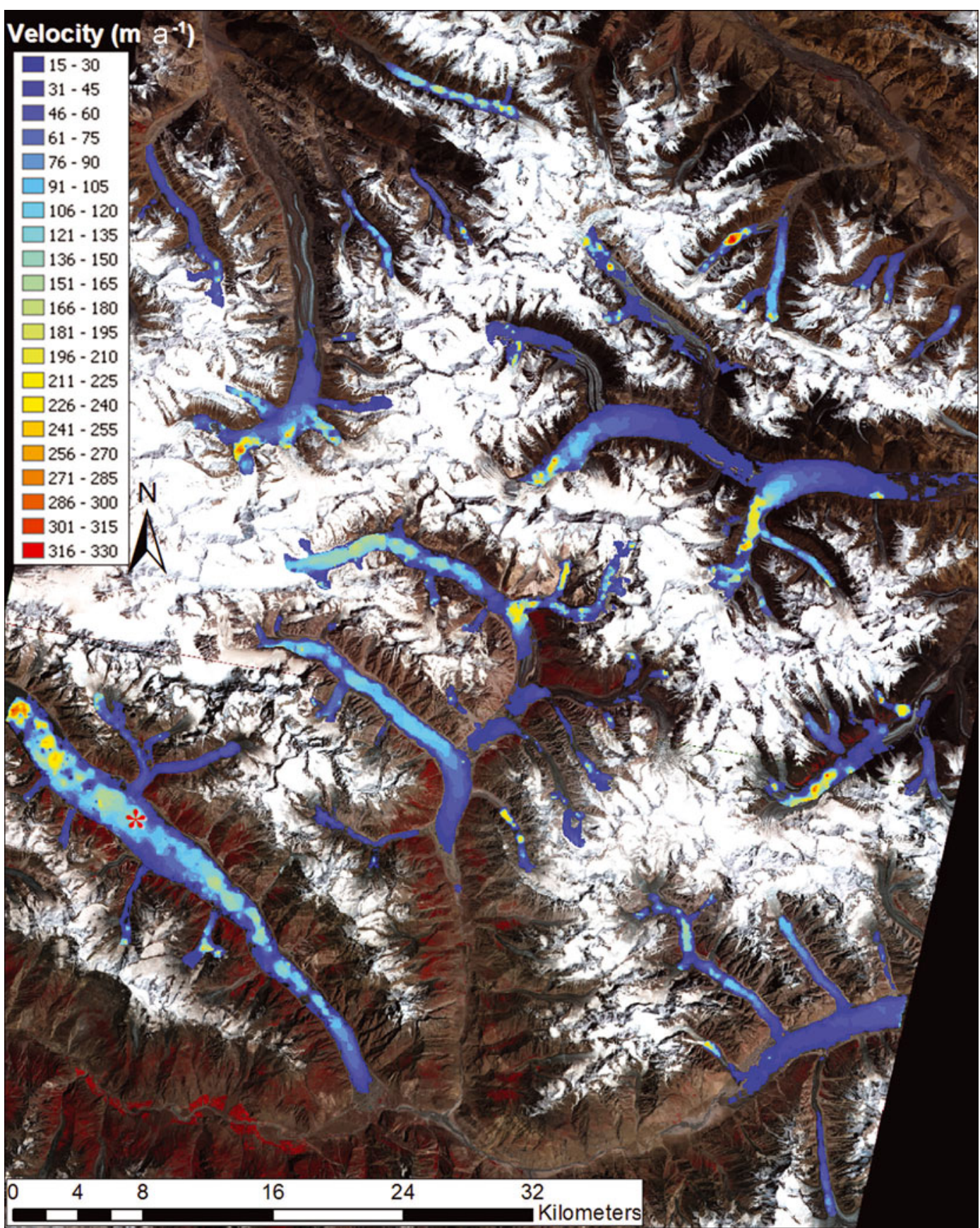

Fig. 5. Overview of glacier velocities across the central Karakoram derived from feature tracking of ASTER satellite scenes from 26 July 2006 and 27 June 2007 (corrected to values of $\mathrm{m} \mathrm{a}^{-1}$ ). Velocities not shown where $<15 \mathrm{~m} \mathrm{a}^{-1}$ or where feature tracking was not successful. The red star on Biafo glacier indicates approximate location of previous velocity measurements made by Hewitt and others (1989).

motion measurements within the current study area. At two points on a transverse profile, Hewitt and others (1989) recorded motion of 0.50 and $0.56 \mathrm{~m} \mathrm{~d}^{-1}$ between 20 July and 12 August $1985 ; 0.22$ and $0.30 \mathrm{~m} \mathrm{~d}^{-1}$ between 12 August 1985 and 29 May 1986; and 0.63 and $0.60 \mathrm{~m} \mathrm{~d}^{-1}$ between 29 May and 30 July 1986 (Fig. 5). These equate to velocities of $108 \mathrm{~m} \mathrm{a}^{-1}$ for the point closer to the glacier margin and $131 \mathrm{~m} \mathrm{a}^{-1}$ for the point closer to the glacier center. These compare to velocities of 111 and $145 \mathrm{~m} \mathrm{a}^{-1}$, respectively, calculated from the average of six feature-tracking points nearest to the locations provided by the map of Hewitt and others (1989). These are both within the stated $15 \mathrm{~m} \mathrm{a}^{-1}$ error for the feature-tracking method, and suggest that the flow of Biafo glacier has changed little over the last $\sim 20$ years. This is supported by field measurements made by the current authors in summer 2005, which indicated that the terminus of Biafo glacier was in the same location, or even slightly advanced, relative to the 1985 position plotted by Hewitt and others (1989).

The results presented here indicate that optical image matching of satellite scenes can allow for regional monitoring of glacier dynamics across remote mountain ranges in the Himalaya, which are difficult to access on the ground. The technique is applicable across all glaciers up to their equilibrium lines, which covers a substantial proportion of ice in this region due to the relatively confined accumulation areas of many of the larger Karakoram glaciers, in contrast to their extensive ablation regions. This builds on the work of Kääb (2005) and Luckman and others (2007), and provides information required for applications such as 
quantifying water resources and surface denudation rates. In addition, satellite-derived velocity determinations can improve understanding of the dynamics of glacier surging, as well as aid in the identification of new surges. The primary limitation of the optical image-matching method is that it requires distinctive surface patterning for the correlations to work. This means that velocities cannot be determined for the accumulation areas of most glaciers due to their snow cover. However, the extensive surface debris cover of the lower parts of most Himalayan glaciers means that these areas are ideal locations for feature tracking.

\section{ACKNOWLEDGEMENTS}

We gratefully acknowledge the K2 2005 medical team, Nazir Sabir Expeditions, and our dedicated porters and guides for assistance in the field. Access to VisiCORR software was kindly provided by T. Benham. ASTER data courtesy of the NASA Jet Propulsion Laboratory, NASA and Global Land Ice Measurements from Space, with assistance from J. Kargel. Funding was provided by the US National Science Foundation (grant BCS-0242339), the US National Geographic Society, NASA (grant NNG04GL84G), the Natural Sciences and Engineering Research Council of Canada, the Canadian Foundation for Innovation, the Ontario Research Fund and the University of Ottawa. Comments from two anonymous reviewers are appreciated and significantly improved the manuscript.

\section{REFERENCES}

Batura Glacier Investigation Group. 1979. The Batura Glacier in the Karakoram mountains and its variations. Sci. Sin., 22(8), 958-974.

Berthier, E. and 7 others. 2005. Surface motion of mountain glaciers derived from satellite optical imagery. Remote Sens. Environ., 95(1), 14-28.

Burbank, D.W. and 6 others. 1996. Bedrock incision, rock uplift and threshold hillslopes in the north-western Himalayas. Nature, 379(6565), 505-510.

Desio, A. 1954. An exceptional advance in the Karakoram-Ladakh region. J. Glaciol., 2(16), 383-385.

Dowdeswell, J.A. and T.J. Benham. 2003. A surge of Perseibreen, Svalbard, examined using aerial photography and ASTER highresolution satellite imagery. Polar Res., 22(2), 373-383.

Fatland, D.R., C.S. Lingle and M. Truffer. 2003. A surface motion survey of Black Rapids Glacier, Alaska, U.S.A. Ann. Glaciol., 36, 29-36.

Finsterwalder, R. 1937. Die Gletscher des Nanga Parbat, Glaziologische Arbeiten der Deutschen Himalaya-Expedition 1934 und ihre Ergebnisse. Z. Gletscherkd., 25, 57-108.

Foster, D.A., A.J.W. Gleadow and G. Mortimer. 1994. Rapid Pliocene exhumation in the Karakoram (Pakistan), revealed by fission-track thermochronology of the K2 gneiss. Geology, 22(1), 19-22.

Gardner, J.S. and K. Hewitt. 1990. A surge of Bualtar Glacier, Karakorum Range, Pakistan: a possible landslide trigger. J. Glaciol., 36(123), 159-162.

Goudie, A.S., D.K.C. Jones and D. Brunsden. 1984. Recent fluctuations in some glaciers of the Western Karakoram mountains, Hunza, Pakistan. In Miller, K.J., ed. The International Karakoram Project, Vol. 2. Cambridge, etc., Cambridge University Press, 411-455.

Hayden, H.H. 1907. Notes on certain glaciers in north-west Kashmir. Rec. Geol. Surv. India, 35(3), 127-137.

Hewitt, K. 1969. Glacier surges in the Karakoram Himalaya (Central Asia). Can. J. Earth Sci., 6(4, Part 2), 1009-1018.

Hewitt, K. 1998. Glaciers receive a surge of attention in the Karakoram Himalaya. Eos, 79(8), 104-105.

Hewitt, K. 2007. Tributary glacier surges: an exceptional concentration at Panmah Glacier, Karakoram Himalaya. J. Glaciol., 53(181), 181-188.

Hewitt, K., C.P. Wake, G.J. Young and C. David. 1989. Hydrological investigations at Biafo Glacier, Karakorum Range, Himalaya; an important source of water for the Indus River. Ann. Glaciol., 13, 103-108.

Kääb, A. 2005. Combination of SRTM3 and repeat ASTER data for deriving alpine glacier flow velocities in the Bhutan Himalaya. Remote Sens. Environ., 94(4), 463-474.

Kick, W. 1962. Variations of some central Asiatic glaciers. IASH Publ. 58 (Symposium at Obergurgl 1962 - Variations of the Regime of Existing Glaciers), 223-229.

Luckman, A., D.J. Quincey and S. Bevan. 2007. The potential of satellite radar interferometry and feature tracking for monitoring flow rates of Himalayan glaciers. Remote Sens. Environ., $\mathbf{1 1 1}(2-3), 172$.

Mason, K. 1935. The study of threatening glaciers. Geogr. J., 85(1), 24-41.

Mayer, C., A. Lambrecht, M. Belò, C. Smiraglia and G. Diolaiuti. 2006. Glaciological characteristics of the ablation zone of Baltoro glacier, Karakorum, Pakistan. Ann. Glaciol., 43, 123-131.

Mayewski, P.A. and P.A. Jeschke. 1979. Himalayan and transHimalayan glacier fluctuations since A.D. 1812. Arct. Alp. Res., 11(3), 267-287.

Raymond, C.F. and 7 others. 1985. Glacier surge mechanism: 1982-1983 surge of Variegated Glacier, Alaska. Science, 227(4686), 469-479.

Scambos, T.A., M.J. Dutkiewicz, J.C. Wilson and R.A. Bindschadler. 1992. Application of image cross-correlation to the measurement of glacier velocity using satellite image data. Remote Sens. Environ., 42(3), 177-186.

Searle, M.P. 1991. Geology and tectonics of the Karakoram mountains. Chichester, Wiley.

Seong, Y.B. and 8 others. 2008. Rates of bedrock incision within an actively uplifting orogen: Central Karakoram Mountains, Pakistan. Geomorphology, 97(3-4), 274-286.

Young, G.J. and J.P. Schmok. 1989. Ice loss in the ablation area of a Himalayan glacier; studies on Miar Glacier, Karakorum Mountains, Pakistan. Ann. Glaciol., 13, 289-293. 